be following nature's indication. The danger from hemorrhage of such a puncture would not be great, since the large vessels lie in a plane posterior to that of the posterior pillar. The knife used should be a right-angled one in order to avoid passing this plane.

Summary.-The whole number of cases examined W 284.

(1) No causative relation could be proved to exist between rheumatism and peritonsillar abscess.

(2) An acute inflammatory condition to the tonsil was found to exist in a sufficient number of cases to suggest that it may be the cause of the infection to the peritonsillar tissue.

(3) A study of the pharyngomaxillary space shows: (a) that its injection with wax on the cadaver may produce an appearance similar to the peritonsillar abscess as seen clinically; (b) that its distance from the surface of the palate may account for the depth of the puncture often needed in order to obtain pus; $(c)$ that the cross action of the muscles covering the space seems a sufficient reason for the closure of punctures made into it; $(d)$ that the supratonsillar fossa and the infratonsillar space offer the surface for puncture most free from anatomical obstruction; $(e)$ that puncture anterior to a plane passing through the posterior pillars cannot injure the great vessels if the knife be kept at all times anterior to such plane; $(f)$ that the space is divided into two cavities by a septum formed by the styloglossus and stylopharyngeus muscles. This in most cases protect's the great vessels from purulent infiltration. Failure of this septum to act explains the cases cited by Bosworth where pus passed along the great vessels into the mediastinum.

In conclusion, I wish to express my thanks to Professor Dwight, of the Harvard Medical School, for both advice and material, and to Dr. H. P. Mosher, for his excellent photographs and drawings, and for much valuable assistance in the preparation of specimens.

\section{IIlinital g্Department.}

\section{A CASE OF SEPTICEMIA TREATED WITH NORMAL SALT SOLUTION.1}

BY OARROLL E. EDSON, A.M., M.D., DENVER, COLO.

Doring the past ten years increasing attention has been directed to the intravascular employment of normal salt solution in cases other than of hemorrhage. Since 1896 especially has its use been tried in cases of general sepsis of varying origin. The considerable and exceedingly interesting literature upon the subject Was well summarized in an article by Dr. 'T. F. Reilly in the Medical Record of November 12, 1898.

I report the following case as a clinical contribution to the increasing number of successful cases that $I$ may help, in whatever small measure, call attention to this ready and simple means of combating what has else been too often a prolonged and hopeless struggle.

I regret the absence of full bacteriological and blood examinations. I should not ask attention to an im. perfect protocol were it not for the striking and suggestive lesson which the case affords.

C. M., age twenty-six, single, an electrical engineer, had been under my close observation for a year, dur-

1 Read before the Medical Society of the State of Colorado. ing which time he had two typical attacks of follicular tousillitis. The family and previous personal history have no bearing upon the illness under consideration. In 1896 and 1897 he had a severe and rather prolonged fever, which may have been typhoid, although reported not to have been. His habits and conduct of life had been exemplary and his health always good.

In the spring of 1898 he was much overworked, and from the first of May until his illness in November had in addition to overwork great business responsibility and anxiety. He was much run down and sleeping poorly. Early in November he suffered from a moderately severe attack of an infectious angina then epidemic in Denver. The throat was intensely sore and there was considerable glandular swelling in the neck. The tonsils were not more involved than the rest of the throat. There was no follicular exudation. No bacteriological examination was made, but the case was similar in every way to others during the epidemic in which cultures were made, and was probably due to a streptococcus infection. Recovery was slow, with great prostration. He returned to work too soon, against advice. During the next week at the office he complained of muscular soreness and weakness.

On November 24th his throat, which had been slightly uncomfortable, became very painful again and there was great backache, headache and high fever. During the next two days the attack ran a course similar to the first, save that there was more general pain tending to localize itself abont the joints. On this account treatment by salicylates and alkalies was given, with anodynes and opiates. No relief was obtained. The muscular and joint pains became worse although there was little or no swelling. There was great difficulty in securing sleep; the temperature remained high, and it was evident that the illness would be prolonged.

On the 28 th the condition became rapidly worse. While the temperature and pulse remained where they had been for several days, in the neighborhood of $101^{\circ}$ and 110 beats per minute, the respirations rose to 35 and soon to 40 . There was no conscious dyspnea, no local pleuritic pain to be distinguished from the great muscular aching everywhere present. Careful examination disclosed nothing more than a small area in the middle of the upper lobe of the right lung, with very slightly heightened percussion note and harsh and distantly exaggerated breathing. The heart was negative, and it may here be stated that daily examination never revealed any evidences of endo- or pericardial lesion.

For the next three days there was much intestinal distention, with a good deal of tenderness, which was not localized. There was some vomiting and troublesome belching. The bowels were finally opened by calomel, salines, and high enemata and the gaseous distention relieved by repeated enemata of asafetida mixture. During the rest of the illness there was fortunately no disturbance from the intestinal tract, and, with the exoeption of a few days during which there was slight febrile albuminuria, the urine remained normal.

The area of suspicious import in the lung did not increase and there was no development of any actual pneumonic process. There was lingering and rather shifting evidence of slight congestion over small patches in the upper right lung for a week or more. The respirations however remained continuously rapid 
and rather shallow. The pains rapidly became absolutely crippling. The knees, ankles, hands, elbows and shoulders were successfully and irregularly invaded.

There was only very moderate swelling, which appeared to be not so much in the joints as an edema in the tissues about them. Over the backs of the hands this was especially noticed. There was at times a very faint blush over small areas, but never noticeable unless looked for. There was also very great tenderness over the muscles. Indeed, it was difficult at times to say whether the pain, which made it almost impossible to move or care for the patient, was caused so much by the motion of the joints as by the pressure upon the muscles. The best, though only slight, relief obtained was from painting the parts with 20 per cent. ichthyol and wrapping them in water with hot bottles outside.

There was almost absolute insomnia, and the few moments' rest obtained was marked by incessant delirious conduct of business affairs. For a while trional gave a little rest, but codeine, chloral, morphine, laudanum or even hydrobromate of hyoscine had little effect in quieting the increasing restlessness, and none procured any satisfactory sleep.

The condition on the 5th of December was most desperate. The temperature chart did not convey any idea of the illness, and is not reproduced for that reason. There was marked emaciation and a frightened look of distress upon the ashy face which can hardly be described. The decubitus was one of complete muscular relaxation, the limbs helpless from the pain, which made the patient moan if he saw any one even approach the bed. The temperature remained steadily between $101^{\circ}$ and $102^{\circ}$, the fever being slightly higher on alternate days; the pulse, varying from 110 to 118 , was weak, small and compressible, but regular. The respirations remained constantly rapid, about 35 , but from time to time there were periods of great distress in breathing unexplained by any discoverable cause. There was very great restlessness, amounting to jactitation much of the time, insomnia and delirium at night, and by day a curious mental state of apparently clear cerebration which, however, was not real. Close watching showed that the mental processes were decidedly clouded and the patient has no recollection whatever of the events of some ten days. There were no rigors or marked fluctuations in temperature, but the man was frequently chilly. Considerable soothing followed hot alcohol baths. Despite nourishment, which was well taken, and abuudant stimulation (sulphate of strychnine, one-thirtieth of a grain subcutaneously every four hours, and five drachms of whiskey every two hours), the patient was evidently fast succumbing to the septic invasion.

The injection of normal salt solution into the tissues seemed to offer slight hope and its use was approved by Dr. W. H. Bergtold and Dr. C. A. Powers, who Baw the patient with me. At four o'clock on the afternoon of December 5th Dr. Powers injected sixteen ounces of hot sterilized salt solution in to the subcutaneous tissues about the breast. Following the injection there was perhaps slight improvement in the restlessness and several quiet naps of from ten to forty minutes. There was an abundant and considerably increased flow of urine in the next twelve hours, nearly double the amount of the corresponding length of time before. Between 12 and 2 A. M. there was a period of very great restlessness and excitement, during which time it was very difficult to keep him in bed.

The morning of the 6th there was no especial im provement in the temperature, pulse or respiration, but the pain was decidedly less and the general condition seemed to warrant a continuation of the treatment. At 8 A. sr. twenty-six ounces were injected slowly into the median cephalic vein. The injection caused great distress, a pulse of 120 and respirations of 40 , with marked excitement for a short time, and profuse perspiration. Two hours later there was a sharp rigor lasting twenty minutes, the temperature rising from $100.6^{\circ}$ to $103.8^{\circ}$. Following this the temperature fell gradually to $99.8^{\circ}$ at 4 P. M., the lowest since the beginning of the illness. During the day the patient was much quieter than he had been and there was no note of any pain. The legs and arms were much less tender and the hands were used a little. At 8 P. s. the temperature rising to $100.8^{\circ}$, and there being a little return of pain, a third injection of eighteen ounces was made, this time under the pectoral muscles, as there seemed less disturbance and equally good results from intracellular injections. Following this there was no chill and only moderate sweating. A good deal of quiet sleep, with only light whispering delirium, was had during the night.

On the 7 th there was much relief from pain in the morning, but during the day the restlessness, delirium and pain returned, and at 4 o'clock P. M. the temperature, pulse and respiration all being higher than for two days, a fourth injection of fourteen ounces was given. All the symptoms at once abated, the pain and the tenderuess first. 'The pulse rate became lower and the quality better. The general expression of improvement was more marked than the signs of the chart.

On the 9th there was a rise of temperature which led to the consideration of further saline infusion, but this was postponed for signs of increasing pain, which did not derelop. A similar rise on the 13th also proved a false alarm.

The subsequent history has nothing of general interest. The mild delirium lasted a long time, as did moderate fever and great weakness. The emaciation was extreme, and the patient absolutely unable to help bimself simply from muscular weakness. Convalescence was necessarily slow after such an illness, but was uninterrupted, and by the first of June, 1899, complete.

The interesting features of this case were, first, the nature and location of the septic process. While I lack all bacteriological proof, I am inclined to think it was due to the streptococcus for the following reasons: It followed directly upon the recrudescence of an infective angina which was clinically the counterpart of others in which the streptococcus was found, and the absence of any suppurative process. A general typhoid infection was ruled out by the clinical picture of the illness, the absence of Widal's reaction and the probable typhoid character of the illness a year before. Nor was the picture one of a pneumococcus infection in the lungs. There was no consolidation, no characteristic expectoration. That the focus of infection starting from the throat became secondarily located in the lungs I am inclined to believe from the coincident appearance of the profound sepsis, the very rapid breathing and the signs pointing to moderate congestion. The shifting nature of these signs was 
also a point in favor of a streptococcus invasion. There may have been some localization in the joints, but the pains seemed rather those of secondury irritation from absorbed toxins. This can of course be only conjecture.

Secondly, the very noticeable relief obtained by use of the salt solution. 'The lessening and cessation of pain, the quieting and clearing effect upon the brain, and the improvement in the pulse and whole general appearance were very striking. That this was not a chance coincidence seems proved by its immediately following four separate injections, the symptoms having returned after the lapve of a number of hours. Cer. tainly up to the time of the first infusion the patient was steadily and rapidly failing; from that time began bis recovery.

Lastly, the ease with which large amounts of salt oolution can be injected under the skin if the fluid be allowed to run in slowly with gentle massage, and the quickness with which it is absorbed. So far as I could see, in this case the relief from the subcutaneous injections was quite as marked as from the intravenous infusion, while the disturbance seemed less. Other observers, however, have reported similar excitement from the subcutaneous use of the fluid. The sweating and free urination were noticeable after each injection.

Should I be so unfortunate as to see another so severe a case, I would make early usse of repeated saline infusions, which can certuinly in the light of our present knowledge do no harm, and which offer such encouraging results.

\section{gqedical geagregg.}

\section{RECENT PROGRESS IN OBSTE'TRICS.}

HY FRANK A. HIGGINB, M.D., HOSTON.

(Conoluded from No. 3, p. 64.)

\section{RETROIDISPLACEMENT OF THE PREGNANT UTERUS.}

STORer ${ }^{6}$ in discussing the subject says that there are no symptoms of consequence uutil about the tenth week, and they may be further delayed in a large pelvis. Spontaueous cure is limited by four things, adhesious, the sacrul angle, the churacter of its displacement and its degree. The patient is often unaware of trouble until pressure symptoms come oll. Urinary symptoms are apt to be the first thing noticed, more or less severe interference with micturition precediug actual retention. This is due to the upward pressure of the cervix on the urethra in versions of the uterus, and to a dragging on the urethra in flexions of the uterus. Constipation is also an early symptom. Upon examining a case of incurceration an exaggerated discoloration of the vulva is seen, and an extreme bulgIng of the perineum, which in one case, the result of a violent effort, caused a central rupture of the perineum and protrusion of the fundus. In flexions the corvix is accessible and not softened as usual in preguancy, but there may be enormous hypertrophy. In uterive Veroions the cervix disappears behind the pubes often out of reach. The digguosis is often very difficult. The displacements may become corrected as pregnancy advances, or pregnaucy may go on to full term, the uterus becoming sacculated. Abortion more frequently

\footnotetext{
- Boston Medioal and Surgloal Jourual, March 9, 1899.
}

occurs, although the retroflexel uterus has difficulty in expelling its contents and the fetus may be retained months after its death. If abortion does not occur grave results generally ensue without treatment, and 77 cases of death have been collected, mainly from sepsis, urewia and rupture of the bladder. 'Treatment is, first, to empty the bladder, which is often a difficult matter, and then attempts at replacement by manipula. tion are made. These consist mainly of depressing the cervix by traction from below and by pressure from above with fingers behind the pubes and at the same time pressing upwards on the fundus to release it, causing the uterus to revolve upon itself rather than attempting to force it up bollily. Elustic pressure in the form of water-bags in the rectum or vagina has been of service. If taxis fuils, the patient's condition is good, and no urgent symptoms present, an expectant policy is advised up to the end of the fourth month, using careful packings, the knee-chest position, etc. Finally, an abdominal operation results in easy replacement without any great danger to the mother and with a better prognosis for the child.

\section{OPERATIONS DURING PRIEGNANCY.}

Noble ${ }^{6}$ reports the results of his experience, which embraces twelve cases: one of myonectomy, one of hystero-myomectomy, one of appendicitis with abscess, one of intestinal obstruction after labor, and one of fistula in ano. The patient upon whom myomectomy was performed aborted, the operation having been undertaken for supposed ovarian tumors. He considers the operation not justifiable under ordinary circumstances during preguancy. One other patient aborted, but the ovum was already dead beiore the operation, which only hastened the inevitable. All of the ovariotumies did well; in none of them was there the least difliculty in performing the operation, and in every way tho patienty made as good recovery as though they hud not been preguant. His experience corresponds with that of other surgeons and is in happy coutrast to the results of the let-aloue practice which so often learis to difficulties in delivery, and unless prompt and intelligent operative measures are taken, to the bruising, infection and necrosis of the tumors, with peritonitis subsequent to labor. In the case of intestinal obstruction, which proved fatul, the operation was complicated by the seven months pregnant uterus, which greatly increased the difficulties of finding the trouble in the abdomen and in dealing with the adherent bowel after it was found. This leads him to believe that it would be wiser in such a case, when dealing with so serious a condition as obstruction, to promptly do hysterectomy and get the big uterus out of the way, and then proceed in a systematic way to do whatever is necessary. He believes that all ovarian tumors which are recognized during pregnaucy should be promptly removed even if quite late, as the risks of operation are much less than the risks of delay. Fibroid tumors should not be operated on during pregnancy unless for some very special reason. With reference to geveral operations in various parts of the body, while there is little danger of bringing on an abortion, yet he believes the iudications for operations should be marked, that is, evidence should be present that the patient's life or bealth would be joopardized by leaving the condition to continue until after labor.

- American Gyneoological and Obstetrical Journal, April, 1899. 